\title{
DESCONSIDERAÇÃO DA PERSONALIDADE JURÍDICA NO PROCESSO TRABALHISTA FACE AO NOVO CÓDIGO DE PROCESSO CIVIL
}

\author{
DISREGARD OF LEGAL ENTITY IN THE LABOR PROCEDURE FACED WITH \\ NEW CIVIL PROCEDURE CODE
}

\author{
Rosana Veloso de Freitas Ayroza ${ }^{1}$ \\ Murilo Braz Vieira ${ }^{2}$
}

\section{RESUMO}

Os proprietários e administradores de empresas, por vezes, utilizam-se da prerrogativa de autonomia patrimonial da pessoa jurídica para eximirem-se da reponsabilidade por suas dívidas. Assim, buscando minimizar os efeitos deste desvio, aplica-se a desconsideração da personalidade jurídica, fazendo com que as dívidas da empresa possam alcançar os sócios ou administradores responsáveis por estas. Por muito tempo, este instituto se viu sem a devida regulamentação processual para sua instauração. Somente após o advento do novo CPC é que esta lacuna legislativa foi preenchida, por meio dos artigos 133 a 137 do código processual. Ante o exposto, o presente trabalho buscou analisar o instituto da desconsideração da personalidade jurídica no processo de execução trabalhista, sob a ótica dos princípios que regem esta especialidade do direito. Para o intento, a metodologia utilizada foi a pesquisa bibliográfica e a análise jurisprudencial. Como resultados, o estudo demonstrou o posicionamento do TRT 10 $0^{\text {a }}$ Região e da ANAMATRA em relação à utilização da nova lei processual, concluindo quanto a incompatibilidade de aplicação das regras no novo Código de Processo Civil.

PALAVRAS-CHAVE: Desconsideração da Personalidade Jurídica; Direito do Trabalho; Norma Processual Civil, Princípios do Processo Trabalhista.

\footnotetext{
${ }^{1}$ Acadêmica de Direito da Faculdade Serra do Carmo. E-mail: rosana.veloso1@gmail.com

${ }^{2}$ Professor da Faculdade Serra do Carmo. Mestre em Prestação Jurisdicional e Direitos Humanos pela Universidade Federal do Tocantins. E-mail: prof.murilobraz@yahoo.com.br
} 


\begin{abstract}
Owners and managers of companies sometimes use the prerogative of patrimonial autonomy of the legal entity to exempt themselves from liability for their debts. Thus, in order to minimize the effects of this deviation, it is applied the disregard of the legal entity, causing the debts of the company can reach the partners or responsible administrators for them. For a long time, this institute was without proper procedural regulation for its establishment. It was only after the advent of the new Civil Procedure Code that this legislative gap was filled, by means of its articles 133 to 137. In view of the above, the present work sought to analyze the institute of the disregard of legal entity in the procedure labor execution, from the point of view of the principles that govern this specialty of law. For the intent, the methodology used was the bibliographical research and the jurisprudential analysis. As a result, the study demonstrated the positioning of the TRT 10th Region and ANAMATRA in relation to the use of the new civil procedural law, concluding about the incompatibility of the application of the rules in the new Civil Procedure Code.
\end{abstract}

KEYWORDS: Disregard of Legal Entity; Labor Law; Civil Procedure; Principles of the Labor Procedure.

\title{
1. CONSIDERAÇÕES INICIAIS
}

A desconsideração da personalidade jurídica é uma teoria oriunda do direito anglo-saxão, chamada disregard of legal entity e introduzida no direito brasileiro em 1969. Tal teoria surgiu ante a utilização da personalidade jurídica como meio de abster-se do pagamento de obrigações sob o argumento de separação patrimonial dos bens da empresa em relação aos bens dos sócios. Assim, era comum a empresa constituir obrigações e se eximir de sua responsabilidade frente elas, pelo fato de não haver patrimônio ligado a seu CNPJ em valores suficientes para saldar as dívidas.

Este artigo se desenvolveu a partir da problematização sobre qual norma utilizar em relação à desconsideração da personalidade jurídica no processo trabalhista. Isto porque o novo Código de Processo Civil (CPC) regulamentou a aplicação deste instituto que, até então, não tinha procedimento descrito em lei. Em síntese, buscou-se discorrer sobre a desconsideração da personalidade jurídica no 
processo de execução trabalhista, com destaque a sua aplicação face ao novo Código de Processo Civil.

Porém, a norma processual civil trouxe etapas cuja aplicação se contrapõe a vários princípios da seara trabalhista, principalmente no que se refere à celeridade do processo. Não obstante, o Tribunal Superior do Trabalho (TST) publicou Instrução Normativa (IN 39) orientando a utilização dos procedimentos da nova lei civil ao processo do trabalho, o que gerou grande oposição dos profissionais deste ramo do direito.

A presença das pessoas jurídicas (entes independentes das pessoas físicas que as conduzem ou deram-Ihe vida) com patrimônio dissociado daquele de seu(s) sócio(s), é importante para o desenvolvimento e estímulo ao crescimento econômico e formalização das atividades empresariais. No entanto, muitos empresários, se utilizam da prerrogativa de autonomia patrimonial para se livrar de suas responsabilidades.

Diante desse cenário, o legislador, preocupado com a manutenção da ordem social, e buscando o fim a que se propôs a entidade jurídica, estabeleceu os casos em que as dívidas da pessoa jurídica alcançam o patrimônio dos sócios, ou seja, os casos em que os membros da sociedade serão responsabilizados pelas dividas da pessoa jurídica. Eis então que surge a possibilidade da desconsideração da personalidade jurídica.

Entendeu-se oportuno tal o direcionamento do estudo ante a mudança no que tange a desconsideração da personalidade jurídica, que antes era caracterizada nos mesmos autos da execução trabalhista e atualmente a nova lei processual civil prevê em seus artigos 133 a 137 a instauração de um incidente apartado para tal.

Em meio a entendimentos diversos, sem previsão em norma trabalhista específica, a coexistência de jurisprudências conflitantes acresce a insegurança do operador do direito, bem como do magistrado, na aplicação do instituto da desconsideração da personalidade jurídica no processo trabalhista, criando um conjunto de decisões discricionárias e muitas vezes contrárias para a mesma situação jurídica. 
Ressalte-se ainda a previsão, no novo código processual civil, de suspensão do processo no momento da instauração da Desconsideração da Personalidade Juródoca (art. 134, §3ํㅡ, CPC), contrapondo-se ao princípio da celeridade, que orienta o processo trabalhista. Porém, existem pessoas que defendem que a nova norma suscita amparo ao contraditório e a ampla defesa ao ser aplicada e por isso há a necessidade de um processo mais detalhado.

O presente estudo apresentará a complexidade e relevância do tema, debruçando-se sobre as divergências doutrinárias e jurisprudenciais, por meio da análise de julgados e da legislação vigente, contribuindo para a formação de uma solução jurídica adequada no que tange a desconsideração da personalidade jurídica no processo trabalhista.

A partir do método dedutivo, a pesquisa foi desenvolvida através de levantamento bibliográfico em doutrinas de direito processual do trabalho, processo civil e direito civil e empresarial, trabalhos relevantes e atuais sobre o assunto, tais como, artigos científicos, revistas, teses e dissertações, além da revisão de jurisprudências do Tribunal Regional do Trabalho 10ª Região e seu posicionamento quanto à utilização da nova lei processual para a desconsideração da personalidade jurídica no processo trabalhista.

\section{DESCONSIDERAÇÃO DA PERSONALIDADE JURÍDICA}

Com o desenvolvimento da sociedade, o homem transforma ao longo do tempo a maneira como garante sua subsistência e, desta forma, organiza sua vida econômica, agrupa-se e estabelece negócios cada vez mais complexos. Sendo o direito uma ciência a serviço das relações sociais, para adaptar-se ao contexto em que a sociedade a que se propõe regular vivencia, nasce a figura da pessoa jurídica, sendo esta, portanto, um produto das necessidades sociais e do desenvolvimento econômico.

Segundo o artigo 45 do atual Código Civil brasileiro: 
Art. 45. Começa a existência legal das pessoas jurídicas de direito privado com a inscrição do ato constitutivo no respectivo registro, precedida, quando necessário, de autorização ou aprovação do Poder Executivo, averbando-se no registro todas as alterações por que passar o ato constitutivo.

Parágrafo único. Decai em três anos o direito de anular a constituição das pessoas jurídicas de direito privado, por defeito do ato respectivo, contado o prazo da publicação e sua inscrição no registro.

Pode-se entender a pessoa jurídica como uma construção técnico jurídica cujo objetivo é proporcionar o livre estabelecimento de relações jurídicas lícitas, contribuindo, desta forma, ao desenvolvimento dos mais diversos negócios (STOLZE e PAMPLONA FILHO, 2012).

Tartuce (2016) conceitua pessoa jurídica como sendo um conjunto de pessoas ou bens, que adquire personalidade própria ante uma ficção legal e, pela própria concepção jurídica, não se confunde com seus membros. Vale ressaltar ainda a presença, no ordenamento jurídico brasileiro, de pessoa jurídica concebida por apenas um titular.

Percebe-se pelos conceitos que a pessoa jurídica foi instituída no ordenamento jurídico como uma confirmação, uma materialização jurídica de algo que já era vivenciado: um agrupamento de pessoas ou bens, funcionando em prol do desenvolvimento de uma atividade econômica, estabelecendo negócios em nome dessas atividades em si, dissociadas de seus membros. Tal confirmação é importante para garantir maior segurança jurídica à atividade empresarial, estimulando, dessa forma, o desenvolvimento econômico.

Isto porque,

A regra é de que a responsabilidade dos sócios em relação às dívidas sociais seja sempre subsidiária, ou seja, primeiro exaure-se o patrimônio da pessoa jurídica para depois, e desde que o tipo societário adotado permita, os bens particulares dos sócios ou componentes da pessoa jurídica serem executados. (TARTUCE, 2016, p.146) 
Ocorre que, muito embora tal possibilidade tenha sido criada visando garantir maior segurança jurídica, muitos se valeram dessa prerrogativa de dissociação patrimonial, utilizando a pessoa jurídica para o fim exatamente oposto a que se propôs o legislador, valendo-se da empresa para lesar terceiros ante o princípio da autonomia patrimonial conferido às pessoas jurídicas.

Com isto, a doutrina e jurisprudências (principalmente inglesas e norteamericanas) deram início à construção da chamada disregard of legal entity (Teoria da Desconsideração da Personalidade Jurídica), mais tarde concretizada em diversos ramos do direito brasileiro, dentre os quais, código de defesa do consumidor de 1990 (art. 28), código civil brasileiro de 2002 (art. 50) e mais recentemente, nos artigos 133 a 137 do Código de Processo Civil publicado em 2015, e que entrou em vigência em 15 de março de 2016.

O instituto da desconsideração da personalidade jurídica trata-se da

possibilidade de afastamento dos efeitos da personalização da sociedade - autonomia e separação patrimonial - nos casos em que a personalidade jurídica fosse utilizada de forma abusiva, em prejuízo aos interesses dos credores (....) permitindo-se, assim, a execução do patrimônio pessoal dos sócios por dívidas da sociedade. (RAMOS, 2014, p.379)

Neste sentido, entende-se que a autonomia da personalidade jurídica, no direito brasileiro não é absoluta. Isto porque diante do caso concreto, o juiz, constatando que o princípio da autonomia processual tem sido utilizado de má-fé pelos empresários (de maneira a desvirtuar sua finalidade precípua de segurança jurídica e dando causa a uma situação completamente inversa: de insegurança dos credores em relação às pessoas jurídicas) pode decretar a desconsideração da personalidade da empresa.

Há de se observar ainda, que a desconsideração não atinge, em regra, toda a sociedade jurídica, mas tão somente o ato específico praticado com má-fé, má gestão, fraude, abuso de direito ou confusão patrimonial, como assevera Coelho (2014). A sociedade continua válida, mesmo que tenha a desconsideração de sua personalidade jurídica decretada. O que se torna inválido é a separação patrimonial 
da empresa em relação ao patrimônio de seus sócios no que tange o ato específico analisado, quando da decisão judicial que decretar tal desconsideração. Venosa corrobora este entendimento afirmando que:

Na realidade, nestas hipóteses, a pessoa natural procura um escudo de legitimidade na realidade técnica da pessoa jurídica, mas o ato é fraudulento e ilegítimo (...). Não se trata de considerar sistematicamente nula a pessoa jurídica, mas, em caso específico e determinado, não a levar em consideração. Tal não implica, como regra geral, negar validade à existência a pessoa jurídica. (VENOSA, 2013, p.297)

Percebe-se o quão preciso é o instituto da desconsideração, visando mesmo alinhar a pessoa jurídica ao fim a que se propôs e tornar justas as relações desenvolvidas pela sociedade para com terceiros, não sendo, portanto, uma ferramenta que limita a autonomia da personalidade jurídica, mas, pelo contrário, fortifica e dá maior segurança à mesma.

O direito brasileiro adota duas teorias para a desconsideração da personalidade jurídica, quais sejam: teoria maior e teoria menor.

Também chamada de teoria subjetiva, a Teoria Maior é a regra presente no ordenamento jurídico brasileiro, observada sobretudo no artigo 50 do Código Civil, no artigo 34 da lei no 12.529/2011, que regulamenta crimes contra a ordem econômica, e no caput do artigo 28 do Código de Defesa do Consumidor.

Segundo esta teoria, para ser possível aplicar a desconsideração da personalidade jurídica é necessário provar: desvio de finalidade, fraude, confusão patrimonial, violação a estatutos ou contrato social e prejuízos a terceiros (GONÇALVES, 2011). É imperioso, portanto, demonstrar o elemento subjetivo (dolo ou culpa) quanto ao mau uso da pessoa jurídica e o prejuízo a terceiros. Somente assim, poderá ser processada a desconsideração de sua personalidade visando atingir os bens dos sócios para reparar os danos sofridos pelos credores da empresa.

Os civilistas Glaciliano e Pamplona Filho (2012) ressaltam a importância da demonstração de tais elementos tendo em vista que entendem que a desconsideração possui natureza punitiva e, sendo sanção, merece 
responsabilidade cuidadosa em sua aplicação, sendo inadmissível a presunção de fraude, abuso e desvio pelo mero inadimplemento. Os autores esclarecem ainda a necessidade de indicação dos atos fraudulentos e bem como das pessoas que se beneficiaram com estes atos.

Observa-se que este foi o pensamento que deu origem ao instituto em questão, uma vez que a Desconsideração da Personalidade Jurídica foi pensada como uma maneira de inibir a utilização fraudulenta da pessoa jurídica com a finalidade de prejudicar terceiros em benefício do comerciante/empresário de má-fé.

Já para a Teoria Menor, ao contrário do postulado na Teoria Maior, não é necessária a comprovação de requisitos subjetivos, portanto, basta a presença de um elemento objetivo, qual seja, a insolvência ante o inadimplemento, para que se possa decretar a desconsideração da personalidade jurídica. Desnecessário assim, a prova de fraude ou o abuso de personalidade (desvio de finalidade ou confusão patrimonial). Neste sentido, Barbosa, Benatto e Soares afirmam que:

Na teoria menor, o princípio da autonomia patrimonial entre a pessoa jurídica e pessoa física é afetado apenas pela inadimplência do débito, negando, na prática, a própria existência, mesmo que ficta, a pessoa jurídica. (BARBOSA; BENATTO; SOARES, 2015, p.206).

A teoria menor sofre duras críticas especialmente dos comercialistas, por entenderem ser uma afronta à autonomia da personalidade jurídica, vez que entendem que a desconsideração é uma repressão ao uso incorreto da pessoa jurídica, sendo assim, coerente é que se demonstre fraude à autonomia patrimonial para que seja decretada. Caso contrário, o credor é que deve suportar o dano da insolvência do devedor, pois não haveria fundamento para a desconsideração (COELHO, 2014).

Esta teoria possui uma aplicação subsidiária, sendo utilizada quando presente uma relação de desigualdade entre a empresa e o credor. Foi pensada inicialmente no âmbito do direito do consumidor, presente no $\S 5^{\circ}$ do Código de Defesa do Consumidor e ainda no artigo 4ํㅡㄹ da Lei de Crimes Ambientais (Lei 9.605/1998).

Baseia-se na ideia de que 
(...) o risco empresarial, inerente às atividades econômicas, não pode ser suportado pelo terceiro que contratou com a pessoa jurídica, mas pelos sócios e/ou administradores desta, ainda que estes demonstrem conduta administrativa proba, isto é, mesmo que não exista prova de culpa ou dolo por parte dos sócios e/ou administradores da pessoa jurídica. Basta a insolvência da empresa para que seus sócios, diante da insuficiência de bens da pessoa jurídica, sejam chamados a ressarcir danos causados aos consumidores e ao meio ambiente. (RIOS, IRIGUARAY, 2005)

Assim, a insatisfação do crédito por parte da pessoa jurídica, cumulada com a solvência dos sócios já preenche os requisitos para a desconstituição da autonomia patrimonial da pessoa jurídica.

Vale ressaltar que a aplicação da desconsideração não enseja invalidação da personalidade jurídica por definitivo, mas aplica-se apenas a situação em que está sendo apurada. Portanto, constata-se que a viabilidade de tal aplicação é analisada especificamente ante um fato concreto.

\subsection{DESCONSIDERAÇÃO DA PERSONALIDADE JURÍDICA NO PROCESSO TRABALHISTA}

O processo do trabalho encontra-se disciplinado dentro das Consolidações da Leis Trabalhistas (CLT). No entanto, percebe-se que esta legislação carece de novas regulamentações, tendo em vista que, desde o seu surgimento na década de 40, muito se alterou no direito como um todo.

Mesmo com limitações, o legislador previu a possibilidade de utilização, no âmbito da justiça trabalhista, de dispositivos legais pertencentes a outros ramos do direito, nos casos de lacuna ou omissão da codificação, ao prescrever nos artigos $8^{\circ}$, 769 e 889, da CLT. Assim, o art. 8ㅜㅗ, nos casos envolvendo a aplicação do direito material, dispõe que:

Art. 8 - As autoridades administrativas e a Justiça do Trabalho, na falta de disposições legais ou contratuais, decidirão, conforme o caso, pela jurisprudência, por analogia, por equidade e outros 
princípios e normas gerais de direito, principalmente do direito do trabalho, e, ainda, de acordo com os usos e costumes, o direito comparado, mas sempre de maneira que nenhum interesse de classe ou particular prevaleça sobre o interesse público.

Parágrafo único - O direito comum será fonte subsidiária do direito do trabalho, naquilo em que não for incompatível com os princípios fundamentais deste.

Já os artigos 769 e 889 preveem a aplicação subsidiária de outros dispositivos legais, especificamente no processo trabalhista. Nestes artigos, percebe-se a necessidade de preenchimento de dois requisitos para colmatação da legislação processual trabalhista pelas regras do processo comum: (1) omissão na lei trabalhista e (2) compatibilidade com os preceitos que fundamentam o direito do trabalho. Importante ressaltar que tais requisitos são cumulativos, sendo assim, necessário que os dois sejam observados para a aplicação das normas do direito comum.

Ocorre que a verificação quanto a omissão da lei trabalhista é de fácil constatação, uma vez que, basta a demonstração da lacuna legislativa, sendo, portanto, uma análise objetiva. O mesmo não se pode dizer quanto ao segundo requisito. Isto porque, a incompatibilidade carece de uma análise subjetiva. Neste ponto é que repousa a discussão em relação ao procedimento a ser adotado para a utilização da desconsideração da personalidade jurídica na seara trabalhista.

Antes da entrada em vigor da Lei n 13.105/2015 (novo código de processo civil), não havia nenhum dispositivo legal que regulamentasse o procedimento inerente a desconsideração da personalidade jurídica. Assim, a justiça trabalhista, respaldada nos argumentos de hipossuficiência do trabalhador (que dificilmente teria condições de provar a má-fé e/ou má gestão empresarial e ainda no caráter alimentar e, portanto, premência, de tais créditos), em analogia ao §5ํำ do art. 28 do Código de Defesa do Consumidor, aplicava, quase que de forma uníssona, a Teoria Menor para a desconsideração da personalidade jurídica, conforme pode ser visto no excerto abaixo:

A justiça do trabalho amplia a despersonalização, levando em consideração a natureza alimentar e superprivilegiada do crédito 
trabalhista, e quando exaurido o patrimônio social. Não execuções, alcança os bens particulares dos sócios e ex-sócios, indistintamente, administradores ou não, respeitando a meação do cônjuge, fundamentando-a na legislação comum. (NASCIMENTO, 2011, p.320)

No entanto, o novo código processual civil, no parágrafo quarto do art. 795, obriga a observância do incidente disciplinado nos artigos 133 a 137 para a aplicação do instituto de desconsideração da personalidade jurídica. A norma prevê maiores requisitos e procedimentos específicos para 0 afastamento da independência patrimonial da pessoa jurídica.

Desta forma, de acordo com o novo CPC, entre os novos procedimentos, há a necessidade de instaurar um incidente para a Desconsideração da Personalidade Jurídica, que pode ser requerido em qualquer fase do processo de conhecimento, no cumprimento de sentença ou mesmo na execução. São legitimados para tal instauração apenas as partes ou o Ministério Público.

Além disso, esse incidente suspende o processo, exceto nos casos em que for requerido pela parte já na inicial. Ainda há de se observar o quanto essa suspensão é longa, tendo em vista que o novo procedimento civilista concede o prazo de 15 (quinze) dias para os representantes da empresa manifestarem-se a respeito de tal instauração.

Nada obstante, o artigo 15 do CPC determina ainda que "na ausência de normas que regulamentem processos eleitorais, trabalhistas ou administrativos, as disposições deste Código Ihe serão aplicadas supletiva e subsidiariamente".

Verifica-se pela leitura do artigo supracitado que o novo CPC não trouxe qualquer requisito de compatibilidade subjetivo, como os descritos no art. 769 da CLT, por isso, muitos têm encontrado repouso para defesa de utilização do novo incidente.

Analisando as divergências jurisprudenciais quanto à aplicação do novo procedimento para a desconsideração da personalidade jurídica na justiça do trabalho, Schiavi (2016) elenca quatro razões para utilização dos dispositivos legais previstos no CPC: 
1- inexistência de legislação processual trabalhista sobre a desconsideração da personalidade jurídica: trata-se de um requisito objetivo, conforme apontado alhures, não havendo margem para discricionariedade;

2 - a utilização das regras de direito material previstas no Código de Defesa do Consumidor e no Código Civil para fundamentar a desconsideração da personalidade jurídica na Justiça do Trabalho: sendo o CDC um direito especial, e uma vez o art. 8 da CLT determinando que o direito comum e não especial é fonte subsidiária, mais correto seria a aplicação do novo CPC em detrimento do CDC como até então vinha ocorrendo;

3 - aplicação do devido processo legal, com a possibilidade do contraditório antes do bloqueio patrimonial: esse argumento se fundamenta no fato de que muitas vezes o sócio nem mesmo consta no polo passivo da demanda e, "surpreendentemente" tem seus bens constringidos pela penhora on-line, procedimento comum nas execuções trabalhistas;

4 - aplicação do procedimento de forma justa e equilibrada: o instrumento específico seria um reforço à legalidade e instrumentabilidade do processo, garantindo que a questão seja amplamente discutida para que haja segurança antes de invadir o patrimônio dos sócios.

Segundo o novo CPC, quando couber a intervenção, em qualquer fase do processo, abre-se o incidente de desconsideração. Tal instauração suspende o processo e o pedido deve ser munido de provas que demonstrem os pressupostos contidos no art. 50 do Código Civil (situações que provem o abuso da personalidade jurídica). Assim, os sócios são citados e começa-se a fase de conhecimento, que culmina com uma decisão interlocutória, cabendo agravo de instrumento.

Por outro lado, não faltam argumentos aos que defendem a inaplicabilidade do incidente previsto no processo comum, principalmente na fase de execução. Isto porque o procedimento de execução trabalhista deve ser célere e urgente, tendo em vista a hipossuficiência do trabalhador e o caráter alimentar de seus créditos.

Argumentam os juristas contrários à aplicação do incidente de desconsideração da personalidade jurídica na forma prevista no novo CPC, que o sócio não é parte, nem terceiro no processo. De acordo com o art. 790, inciso II do 
CPC, os sócios são responsáveis patrimoniais e seus bens estão sujeitos à execução. Além disso, o caput do art. $2^{\circ}$ da CLT esclarece que os riscos da atividade econômica devem ser responsabilidade de seus contratantes. Portanto, a luz dos dispositivos legais supracitados, entende-se que a responsabilidade do sócio é subsidiária em face da pessoa jurídica.

Schiavi (2016) acrescenta que o processo trabalhista deve servir para instrumentalizar o direito do trabalho e, desta forma, não pode violar tal direito. No entendimento do autor, tal situação ocorre nos casos em que a desconsideração é aplicada nos moldes do novo CPC. Tendo em vista a possibilidade ínfima do trabalhador demonstrar ato culposo do sócio da empresa, como determina a instauração do incidente pelo CPC, tal exigência ignoraria a condição de fato do trabalhador, tornando, praticamente, inviável a desconsideração.

No mesmo sentido, o art. $893 \S 1^{\circ}$ da CLT, elucida que "os incidentes do processo são resolvidos pelo próprio Juízo ou Tribunal, admitindo-se a apreciação do merecimento das decisões interlocutórias somente em recursos da decisão definitiva". Tem-se então, a autorização do contraditório diferido, sendo esta uma das particularidades do processo trabalhista, o que contrapõe a tese que defende a implementação do novo procedimento sob o argumento de respeito ao contraditório, uma vez que não há exclusão de tal princípio processual, mas apenas uma postergação do contraditório.

Vale destacar que o artigo 889 da CLT supracitado autoriza, quando da execução trabalhista, a utilização de regras do procedimento de execuções fiscais e estes, por sua vez, também autorizam o contraditório "a posteriori" como forma de garantir a execução.

Assim, a instauração do incidente de desconsideração da personalidade jurídica como procedimento autônomo trazida no CPC, para muitos, significaria a violação de preceitos trabalhistas como reconhecimento da hipossuficiência do trabalhador, autorização do contraditório diferido, celeridade do processo trabalhista, irrecorribilidade das decisões interlocutórias, simplificação das formas e procedimentos, entre outros. 


\subsection{PREJUÍZOS DA APLICAÇÃO DO INCIDENTE DE DESCONSIDERAÇÃO DA PERSONALIDADE JURÍDICA DO NOVO CPC AOS PRINCÍPIOS DO PROCESSO TRABALHISTA}

O direito do trabalho, assim como quaisquer demais ramos do direito, possui princípios de o individualizam e revelam o por quê de existir. Os princípios estão ligados aos preceitos primários, à fonte material do direito que substanciam.

O "acontecimento" no mundo real (fonte material) é responsável pelo surgimento da necessidade de amparo legal (fonte formal) como meio de suprimento de um novo fato social. Assim surge um conjunto de normas que dá efetividade ao ramo do direito. Esse conjugado normativo possui um elo que o une à fonte material e torna o direito coeso e autônomo. Pode-se dizer que tal elo é formado pelo grupo de princípios que o resguardam.

Desta forma, os princípios são uma das fontes mais importantes do sistema jurídico porque revelam sua identidade e norteiam a aplicação do direito em questão, sendo regramentos básicos, fundamentam o instituto do direito material e processual do trabalho, representando, assim, a parte mais importante da matéria, pois servem de base para todo o conteúdo do direito específico que fundamentam, (PEREIRA, 2014).

Portanto, uma norma qualquer (material ou procedimental) que se proponha a servir um ramo do direto não pode estar desconexa aos seus princípios, pois não haveria como concretizar o direito que se pretende sem a "ponte" que o leva à fonte material.

Para Martins Filho (2013), os princípios são postulados que dão sentido à norma trabalhista e, assim sendo, possuem critérios, por vezes distintos dos demais ramos do direito, o que confere certa autonomia ao direito do trabalho. Esclarece ainda 0 autor que os princípios em geral possuem três funções básicas: (1) informadora, pois orientam a formulação de leis, fundamentando estas normas; (2) normativa, devendo ser utilizados quando houver lacuna e/ou omissão da lei, sendo, portanto, fonte supletiva; e (3) interpretativa, uma vez que conduz a aplicação da 
norma ao caso concreto, facilitando sua compreensão e orientando os casos de conflito aparente de normas.

A produção de normas não atreladas aos princípios do ramo do direito corresponderia a adequação do fato à norma para prestação jurisdicional, quando na verdade, o sistema jurídico é que deve servir à regularização dos fatos sociais. Neste sentido, as normas devem adaptar-se para suprir adequadamente as mazelas que almejam extinguir.

Uma análise mais detalhada do incidente de desconsideração da personalidade jurídica previsto no novo CPC revela incoerência deste procedimento com os princípios trabalhistas, especialmente no que tange a efetividade da tutela executiva e a celeridade e economia processual (SHIAVI, 2016; CLAUS, 2016). O que não significa que a norma é um equívoco em si, mas tão somente que a mesma não se amolda às necessidades deste ramo do direito.

Dentre as incoerências aludidas, evidencia-se logo no primeiro artigo que regula 0 incidente. $O$ artigo em questão exige a manifestação da parte para a apreciação da desconsideração da personalidade jurídica, contrapondo-se, desta forma, ao princípio da indisponibilidade do direito do trabalho, segundo o qual, o magistrado, pode promover de ofício a execução (art. 878, CLT).

Segundo Claus (2016), a exigência de iniciativa das partes na desconsideração da personalidade jurídica pode ser considerado um retrocesso social histórico, que representa uma afronta aos princípios trabalhistas, uma vez que vai de encontro à garantia de efetividade da jurisdição, contrapondo-se, portanto, à norma constitucional (art.5ํ, XXXV e LXXXVIII, CF).

Em interpretação dos arts. 878 e 765 da CLT conforme a Constituição, no subsistema jurídico trabalhista a desconsideração da personalidade jurídica da sociedade empresarial de ofício sempre foi compreendida como a expressão concreta do princípio da proteção na fase de execução do procedimento laboral (...) A jurisprudência trabalhista consolidou essa compreensão ao longo de sete décadas. (CLAUS, 2016, p.69)

Outra incompatibilidade do novo procedimento civilista em relação ao processo trabalhista ocorre diante da responsabilização do credor na colheita de 
provas como requisito para demandar a desconsideração da personalidade da empresa (SCHIAVI, 2016) Transferir ao empregado o ônus da prova não só ofende o princípio de proteção ao trabalhador como também torna praticamente inviável tal procedimento na seara trabalhista.

Isto porque não há como se apresentar razoável a exigência de demonstração, por parte do trabalhador, de confusão patrimonial, desvio de finalidade, violação a estatutos ou contrato social e demais requisitos subjetivos. Tal exigência seria uma deslealdade para com o empregado tendo em vista que todas estas provas se concentram na posse da empresa, além da condição de desigualdade da relação trabalhista. Assim, mais que não proteger o trabalhador, a aplicação de tal regra aumentaria o abismo entre um polo e outro da demanda empurrando ainda mais abaixo o trabalhador e favorecendo a sociedade empresária.

Observa-se outro antagonismo da nova legislação processual em relação ao direito trabalhista. Ao prever a suspenção do processo quando da instauração do incidente de desconsideração, o dispositivo legal contrapõe aos princípios de concentração dos atos, celeridade processual, simplicidade das formas e procedimentos e ainda o da própria proteção ao trabalhador, já que os créditos trabalhistas têm natureza alimentar (SCHIAVI, 2016; CLAUS, 2016, SILVA, 2016; PEREIRA, 2016).

Almeida (2015) ressalta que a existência de um procedimento especial no processo trabalhista se justifica em virtude da transcendência econômica, humana, política e social do Direito do Trabalho, sendo indispensável à realização concreta deste direito uma aplicação complementar qualificada do novo CPC, de forma a respeitar os princípios do subsistema laboral.

Ante o exposto, a doutrina majoritária tem se posicionado de forma a absterse da utilização da nova lei na justiça trabalhista no que tange a desconsideração da personalidade jurídica. Isto porque o instituto deve ser aplicado atendendo aos princípios próprios deste subsistema jurídico, garantindo a celeridade e a efetividade de que carece o procedimento trabalhista. 


\section{IN 39 DO TST e ENUNCIADO № 45 DO TRT 10ํㅡ REGIÃO}

Um ano após a entrada em vigor do novo CPC, o TST editou instrução normativa no 39 (IN 39), que se dispõe a definir quais normas da processualística civil seriam aplicadas no âmbito do processo trabalhista. A instrução causou indignação de muitos operadores do direito, sobretudo da Associação Nacional dos Magistrados da Justiça do Trabalho - ANAMATRA.

A associação em questão questionou a constitucionalidade formal e material da instrução por meio de ADI 5516, dois meses após a vigência da IN 39,. O primeiro ponto argumentado pela ANAMATRA diz respeito à competência, entendendo que o TST invadiu reserva do legislador ordinário federal, afrontando o inciso I do art. 22 da Norma Maior, além dos artigos 5º II e 96, I, “a”, ambos da CF, vez que não possui competência constitucional ou legal para regulamentar lei federal. Argumentam ainda na ADI a violação ao Princípio de Independência dos magistrados, pois estariam vinculados à norma editada por tribunal incompetente, sem possibilidade de interpretar e aplicar a lei de forma diversa ante o caso concreto.

Como a ADI ainda não foi julgada, a ANAMATRA resolveu questionar a Corregedoria, cujo entendimento é de que a instrução normativa não possui caráter vinculante e, portanto, sua inobservância não admite correição parcial. Sendo assim, os Tribunais Regionais, assim como os magistrados, individualmente, têm se posicionado e adotado entendimentos diversos.

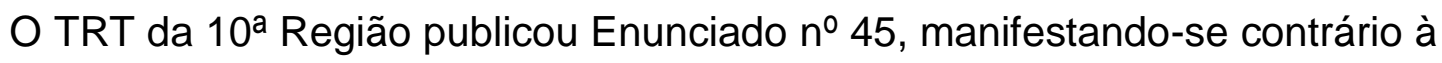
aplicação do CPC ao processo do trabalho, no que tange a desconsideração da personalidade jurídica, o que vai de encontro ao art. $6^{\circ}$ da IN 39 do TST.

Art. $6^{\circ}$ Aplica-se ao Processo do Trabalho 0 incidente de desconsideração da personalidade jurídica regulado no Código de Processo Civil (arts. 133 a 137), assegurada a iniciativa também do juiz do trabalho na fase de execução (CLT, art. 878).

§ 1 으 Da decisão interlocutória que acolher ou rejeitar o incidente:

I - na fase de cognição, não cabe recurso de imediato, na forma do art. 893, § $1^{\circ}$ da CLT; 
II - na fase de execução, cabe agravo de petição, independentemente de garantia do juízo;

III - cabe agravo interno se proferida pelo Relator, em incidente instaurado originariamente no tribunal (CPC, art. 932, inciso $\mathrm{VI}$ ).

§ 2 A instauração do incidente suspenderá o processo, sem prejuízo de concessão da tutela de urgência de natureza cautelar de que trata 0 art. 301 do CPC.

O tribunal entende que os procedimentos da instrução normativa não se amoldam aos princípios trabalhistas, sobretudo em relação à celeridade, já que o CPC impõe a suspensão do processo. Assim, a aplicação dos procedimentos trazidos com a nova regra processual civil causaria obstáculo à efetividade dos créditos do trabalhador (PEREIRA, 2016; CLAUS, 2016; SILVA, 2016).

A manifestação desfavorável do TRT 10aํ Região é, portanto, um alinhamento ao que preceitua o art. 765 da CLT, pois,

Por força do direito das partes e do dever correlato do juiz do trabalho, constitui dever dos órgãos da Justiça do Trabalho: adotar as medidas necessárias à identificação e ao combate dos fatores geradores de morosidade na tramitação dos processos (definição dos pontos de estrangulamento do procedimento), observando-se que divergências meramente doutrinárias e acadêmicas devem ser abandonadas em favor da efetividade da tutela jurisdicional (...). (ALMEIDA, 2015, p.301)

Desta forma, entende-se a validade e importância da normatização dos procedimentos para a desconsideração da personalidade jurídica trazidos no novo CPC ante a carência de norma procedimental específica vivenciada até então pelo direito brasileiro. No entanto, é imprescindível a compreensão de que o novo regramento não se aplica ao Direito do Trabalho, vez que se verificam diversas incompatibilidades entre estes novos procedimentos e os princípios específicos laborais.

\section{CONSIDERAÇÕES FINAIS}

Verificou-se a seriedade do instituto de desconsideração da personalidade jurídica nos mais diversos ramos do direito. De fato, mostrou-se instrumento capaz 
de fortificar e adequar a finalidade para a qual se constituem as empresas, dando validade à autonomia patrimonial e realinhando-a quando da utilização da personalidade jurídica como meio de desvio de responsabilidades.

Analisando o Direito do Trabalho como uma especialidade jurídica e, ante seu carácter sui generis, entende-se explicável a possibilidade de confronto entre seus procedimentos e aqueles do ramo do Direito Civil. Somando-se a isto, o fato de que o direito laboral não possuir código processual específico, mas tão somente procedimentos descritos na CLT, ainda na década de 40, percebe-se o quão cuidadosa deve ser a aplicação da norma trabalhista.

Assim, a própria CLT autoriza, e é comum, a utilização de regramentos de outros ramos do direito para satisfação de lacunas quando da aplicação do direito do trabalho. Nada obstante, súmulas, orientações jurisprudenciais, instruções normativas, entre outras ferramentas, são de grande apoio aos aplicadores deste ramo do direito.

Ante a ausência de norma procedimental para a aplicação da desconsideração da personalidade jurídica, a justiça trabalhista vinha aplicando a Teoria Menor, entendendo que ela se harmoniza melhor aos princípios deste ramo do direito. Tal aplicação vai ao encontro dos princípios da alteridade, economia processual e celeridade que regem o processo trabalhista.

Ocorre que o novo CPC, vigente a partir de março de 2015, trouxe a regulamentação processual para a instauração do incidente de despersonalização e, com isto, o TST publicou IN 39 esclarecendo procedimentos para a utilização da nova lei processual ao ramo trabalhista. Porém, muitos juristas e operadores do direito manifestaram-se contrários, tendo em vista que o novo regramento traz procedimentos que dificultam a execução trabalhista e se contrapõem, em diversos pontos, aos princípios do sistema jurídico laboral.

Assim, em respeito aos anos de luta dos trabalhadores pela conquista de seus direitos, e ainda, aos princípios que balizam a existência do próprio Direito do Trabalho, tribunais e magistrados, especialmente a ANAMATRA e o TRT 10 Região, objetos deste estudo, posicionaram-se desfavoráveis à aplicação dos 
procedimentos do novo CPC, o que resultou a ADI 5516 (ainda não julgada) e o Enunciano no 45 do TRT 10ํㅡㄹ Região.

Desta forma, o incidente de desconsideração da personalidade jurídica, nos moldes do novo CPC, se mostra impróprio ao processo trabalhista, vez que rompe com princípios deste ramo do direito, contrariando, sobretudo, a simplicidade dos procedimentos e a celeridade do processo do trabalho.

Inadmissível que normas processuais rompam o direito que pretendem materializar. Isto é o que defende a legislação trabalhista ao determinar que a compatibilidade com os procedimentos do processo trabalhista é requisito para a utilização subsidiária das normas do processo comum.

Sendo assim, os procedimentos civilistas prejudicam a efetividade da prestação jurisdicional trabalhista e, por isso, sua utilização torna-se inadequada à justiça do trabalho.

\section{REFERÊNCIAS}

ALMEIDA, Cleber Lúcio de. Os reflexos do código de processo civil de 2015 no direito processual do trabalho: prazos processuais e duração razoável do processo. Revista do Tribunal Regional do Trabalho da 3ª Região. Belo Horizonte, v. 61, n. 92, p. 295-311, jul./dez. 2015.

BARBOSA, Marco Antonio; BENATTO, Pedro Henrique Abreu e SOARES, Roger da Silva Moreira. O novo código de processo civil: desconsideração da personalidade jurídica e a penhora on-line no processo do trabalho. Revista de Direito do Trabalho. Vol. 165. Ano 41. p.197-213. São Paulo: Ed. RT. Set-out, 2015.

BRASIL, Consolidação das Leis do Trabalho. Decreto Lei n. 5452 de 1ำ de maio de 1943. Aprova a consolidação das leis do trabalho. Disponível em: http://www.planalto.gov.br/ccivil 03/decreto-lei/Del5452.htm. Acesso em: 27 set. 2016.

Código Civil Brasileiro. Lei n. 10.406, de 10 de janeiro de 2002. Disponível em: http://www.planalto.gov.br/ccivil 03/leis/2002/L10406.htm. Acesso em: 27 set. 2016.

Código de Processo Civil. Lei n. 13.105, de 16 de março de 2015. 2018/2015/lei//13105.htm. Acesso em: 27 set. 2016. 
COELHO, Fabio Ulhoa. Manual de Direito Comercial: Direito de Empresa. 26. ed. São Paulo: Saraiva, 2014.

CLAUS, Ben-Hur Silveira. O incidente de desconsideração da personalidade jurídica previsto no CPC 2015 e o direito processual do trabalho. Revista do Tribunal Regional do Trabalho da 10ª Região. V. 20. Ano 2016. P. 54-89. Brasília: Escola Judicial, Ago, 2016.

GAGLIANO, Pablo Stolze; PAMPLONA FILHO, Rodolfo. Novo Curso de Direito Civil, volume 1: parte geral. v. 1. 14. ed. São Paulo: Saraiva, 2012.

GONÇALVES, Carlos Roberto. Direito Civil 1 Esquematizado: Parte Geral, Obrigações, Contratos. São Paulo: Saraiva, 2011.

MARTINS FILHO, Ives Sandra da Silva. Manual Esquemático de Direito e Processo do Trabalho. 21. ed. São Paulo: Saraiva, 2013.

NASCIMENTO, Amauri Mascaro. Iniciação do Processo do Trabalho. 6. ed. São Paulo: Saraiva, 2011.

PEREIRA, Alexandre Pimenta Batista. Reflexões sobre o Enunciado 45 da EJUD do TRT 10aㅡ Região. Revista do Tribunal Regional do Trabalho da 10ª Região. V. 20. Ano 2016. P. 33-36. Brasília: Escola Judicial, Ago, 2016.

PEREIRA, Leone. Manual de Processo do Trabalho. 3. ed. São Paulo: Saraiva, 2014.

RAMOS, André Luiz Santa Cruz. Direito Empresarial Esquematizado. 4. ed. São Paulo: Método, 2014.

RIOS, Aurelio Virgilio Veigas; IRIGARAY, Carlos Teodoro Hugueney. O Direito e o Desenvolvimento Sustentável: Curso de Direito Ambiental. São Paulo: Peirópolis, 2005.

SCHIAVI, Mauro. Manual de Direito Processual do Trabalho. 10. ed. São Paulo: LTr, 2016.

SILVA, Laryssa Marcelino da. Desconsideração da Personalidade Jurídica no Processo do Trabalho: Inaplicabilidade das Invações do Novo Código de Processo Civil. Revista do Tribunal Regional do Trabalho da 10ª Região. V. 20. Ano 2016. P. 122-127. Brasília: Escola Judicial, Ago, 2016.

TARTUCE, Flavio. Manual de Direito Civil: volume único. 6. ed. São Paulo: Método, 2016.

VENOSA, Silvio de Salvo. Direito Civil: Parte Geral. 13. ed. São Paulo: Atlas 